\title{
Empirical Study on Impact of the High-speed Train to Regional Economic Development
}

\author{
Lai Fengbo ${ }^{1,2, a,{ }^{*} \text {, Sun Chuiqing }}{ }^{2, b}$, Rong Chaohe ${ }^{1, c}$ \\ ${ }^{1}$ School of Economics and Management of Beijing Jiaotong University, China \\ ${ }^{2}$ School of Management of Shandong Jiaotong University, China \\ asd_laifengbo@163.com, ${ }^{\text {b } 404830791 @ q q . c o m, ~}{ }^{c}$ chrong@bjtu.edu.cn
}

Keywords: High-speed Train, Regional Economic Development, Three Industries, Effect.

Abstract. High-speed train (HST), as a mode of high efficient rail transportation, which has evidently shaping effect on its regional economic development, has in recent years greatly shortened time-space distances between regional areas. This article has provided the causal relationship between HST and its regional economic aggregate, adopting the Granger Causality Test, on the basis of which we put forward the influences on the industrial structure and the tertiary industries, and conduct the related empirical study on the opening of Wuhan-Guangzhou HST and its effect on its areas along this line. According to this analysis, HST service can boost its regional economic aggregate, as well as the transformation and upgrade of its industrial structure, with its hysteresis quality, though. With the development of HST, the tertiary industries will grow rapidly but slow continuously down the impact on the third industry.

\section{Introduction}

The first high-speed train, appeared in Japan in 1964, which drew the attention of the world in its economic and social effectiveness, greatly promoted the rapid development of the areas along its line. High-speed Train (HST), which has ever since started from scratch and developed its mushroom growth, has now become a most important driving force in stimulating the economic development of related regional areas and evolving its spatial framework. As a mode of modern transport, HST has been playing more and more crucial role in the development of this economic society.

\section{HST's influential paths for regional economic development}

Comparing with the other transport modes, HST service has an advantage of mass passenger or freight transports and shortened haulage. Judging from the recent years, HST service has a profound impact on boosting its regional economic aggregate, transforming regional industrial structure and time-spatial coordination, circulating the production factors, developing the urban and rural structures and speeding the urbanizations. Moreover, it causes the proportional changes of the three industries, with the hint of further development and so-called Halo Effect. Therefore, probing the factors of HST's influential paths will be of great reference value in the coordinating the future high-speed trains and regional economic development, guiding the layout and construction of China's high-speed trains. The influential paths are as follows:

Regional economic aggregate. From the perspective of production factors, HST's influence on regional economic development has the following two aspects: (a) Social Capital According to The Theory of Investment Multiplier, the variation of investment amount can cause the chain reaction of national income, and the latter should increase larger amount than the original investment amount and vice versa. Generally, the increase of HST's investment will amplify the scale of production means, and further increase the social employment and consumption and accordingly benefit the national income. Hence, investing the HST directly increases the total social demand and indirectly pull the growth of the local economy. (b) Human Capital. As an efficient and rapid mode of transportation, constructing more unimpeded HST service will stimulate the mobility and availability of human capital among the 
related areas and spread its liquidity of techniques, information and capital in a larger scale. Thus we can obtain sensible and efficient allocation of regional production factors.

Regional industrial structure. Accelerating the industrial structural transformation. onstruction of HST, which can optimize and upgrade its industrial structures, advances the independent and collaborative innovations of the regional industries along the rail lines. For one thing, as to rail industries, China has succeeded in internally developing CRH and its packaged technology with the speed of $350 \mathrm{~km}$ and $380 \mathrm{~km}$. Also China has, with its HST technique system and manufacture platform of proprietary intellectual property rights and global advanced level, greatly improved high-tech innovation and technological levels of train. Relying on the development of high-speed trains, train equipment manufacture industries have also expanded rapidly. "Made in China" technology has evolved from inferior to superior, from labor-intensive to technology-intensive. For another, the development of HST also brings about the collaborative innovations of the regional industries.

Optimizing the industrial distribution of regional cities. The construction and opening of HST service will be beneficial to the urban scale and structure and establish a rational hierarchical system of cities. As mentioned above, HST will drive the related industries to increase investments to extend their business. The additional investments will greatly trigger a new cycle of market effect and the cycle accumulation will come into being, which will have substantial improvement of urban attraction of these regions. Considering the diversities of the industrial structures and scales, cities along the same rail line will embody great different expansion in oriental and spatial layouts.

\section{Empirical test on the regional economic effect of HST}

To start from the macro-view, the production factors are allocated rationally and efficiently in a far-ranging spatial scale by HST, and thereby drives the growth and blossom of regional economic aggregate. In the micro-view, construction and opening of HST leads to the new path of regional production factors, which is introduced to the areas along the rail line, through the powerful time-space contraction effect, and promotes the transformation of industrial structures. Thus it has broken the original balanced pattern of demand of the regions and brought along the development of related industries, as well as the multiplier effect of demand and investment. The followings are the empirical tests on the HST grounded on the macro and micro aspects.

In China, HST shows its unique superiority in relative to the other mode of transportations. Let's use the Granger Test of Causality to see the influences on the regional economic growth by HST. Under the circumstances of China's economic statistics, the economic aggregate of the regions along the train lines is on the basis of GDP. Thus this paper further proves the leading role of regional economic aggregate by HST, citing the theory that increasing the total GDP is in place of increasing the regional economic aggregate after its opening of HST. The following structural models are:

Unconditional limit model:

$$
Y_{t}=\alpha+\sum_{i=1}^{m} \alpha_{i} \Delta Y_{t-i}+\sum_{j=1}^{k} \beta_{j} \Delta X_{t-j}+\varepsilon_{t}
$$

Conditional limit model:

$$
Y_{t}=\alpha+\sum_{i=1}^{m} \alpha_{i} \Delta Y_{t-i}+\varepsilon_{t}
$$

Where ${ }^{\varepsilon_{t}}$ refers to White Gaussian Noise, $\alpha, \beta$ refer to regression coefficient, ${ }^{t}$ sample size, $m, k$ respectively variable hysteresis order, form (3-11) residual sum of square ${ }^{2 S S_{1}}$; form (3-11) regression sum of squares $E S S_{0}$. Original hypothesis $H_{0}: \beta_{j}=0$; Alternative hypothesis $H_{1}: \beta_{j} \neq 0(j=1,2, \ldots \ldots, k)$, the statistical magnitude is: 


$$
F=\frac{\left(E S S_{0}-E S S_{1}\right) / m}{E S S_{1} /(n-k-m-1)} \rightarrow F(m, n-k-m-1)
$$

Namely, statistic $\mathrm{F}$ has the first degree of freedom $m$, and the second degree of freedom $n-k-m-1$. If $\mathrm{F}$ Test Value is larger than the critical value of standard $\mathrm{F}$ distribution, we can reject its original hypothesis and conclude Granger explains the variation of X reasoning that of $\mathrm{Y}$.

According to the annual data of investment on HST and growth of GDP within the years of 2006 2014, we have conducted Granger causality test and obtain the result as Table 1.

Table1 High Speed Rail Investment and GDP growth in the amount of Granger causality test Granger Test

\begin{tabular}{|c|c|c|c|}
\hline & & $\begin{array}{l}\text { 1-year } \\
\text { lag-phase }\end{array}$ & $\begin{array}{l}\text { hypothetical probability } \\
\text { rejection }\end{array}$ \\
\hline original hypothesis: & Sample numbers & F test statistic & $(\mathrm{P})$ \\
\hline I not Granger cause of $\Delta \mathrm{G}$ & 9 & 1.74297 & 0.15724 \\
\hline \multirow[t]{2}{*}{$\Delta \mathrm{G}$ not Granger cause of I } & & 0.37762 & 0.49328 \\
\hline & & $\begin{array}{l}\text { 2-year } \\
\text { lag-phase }\end{array}$ & $\begin{array}{l}\text { hypothetical probability } \\
\text { rejection }\end{array}$ \\
\hline original hypothesis: & Sample numbers & F test statistic & $(\mathrm{P})$ \\
\hline I not Granger cause of $\Delta \mathrm{G}$ & 8 & 5.48167 & 0.10223 \\
\hline \multirow[t]{2}{*}{$\Delta \mathrm{G}$ not Granger cause of I } & & 0.49902 & 0.61051 \\
\hline & & $\begin{array}{l}\text { 3-year } \\
\text { lag-phase }\end{array}$ & $\begin{array}{l}\text { hypothetical probability } \\
\text { rejection }\end{array}$ \\
\hline original hypothesis: & Sample numbers & F test statistic & $(\mathrm{P})$ \\
\hline I not Granger cause of $\Delta \mathrm{G}$ & 7 & 7.58297 & 0.01002 \\
\hline \multirow[t]{2}{*}{$\Delta \mathrm{G}$ not Granger cause of I } & & 1.32668 & 0.25175 \\
\hline & & $\begin{array}{l}\text { 4-year } \\
\text { lag-phase }\end{array}$ & $\begin{array}{l}\text { hypothetical probability } \\
\text { rejection }\end{array}$ \\
\hline original hypothesis: & Sample numbers & F test statistic & $(\mathrm{P})$ \\
\hline I not Granger cause of $\Delta \mathrm{G}$ & 6 & 3.26692 & 0.01923 \\
\hline$\Delta \mathrm{G}$ not Granger cause of I & & 1.00459 & 0.47218 \\
\hline
\end{tabular}

Of Table.1, the probability of F-statistic and its null hypothesis tenability is significance level. The test result shows that under the $98 \%$ confidence level, with its lag-phase of 3, development of HST explains the economic growth of Granger cause; and similarly under 95\%, with lag-phase of 4 , and equally under $85 \%$ with lag-phase of 2 as well. However, when lag-phase becomes 1 , investment on HST has no significance of Granger cause for economic growth.

In a word, Granger causality test can explain one of the significant factors for its regional economic growth by the investment, development and construction of HST. Within several years of its opening, the growth trend and amount of economic aggregate can gradually emerge, which illustrates that it is apparent for HST to drive and stimulate the regional economic development. Meanwhile, its economic acceleration is not significant at the initial period but with a lag phase, which illustrates, for any train areas, that construction of HST may not get instant effect on its economics, for it has a long and continuous process, and its leading role may emerge gradually accompanying the factor mobility and industrial spatial aggregation.

Take an example of the early Wuhan-Guangzhou HST, it has an apparent proportion variation on the three industry structures. And as time goes by, this effect will gradually deepen. In general, the primary industry's proportion along the train line has a declined trend, but the secondary and tertiary industries has slight different trend. For instance, in Fig 3, the three industrial structures for capital cities of Wuhan, Guangzhou, and Changsha have been optimized before and after its openings. The 
proportions for three industries are shown as the following. Wuhan in the year of 2007: 4.11:45.83:50.06; but in 2014: 3.5:47.5:49. Guangzhou in 2007: 2.11:39.48:58.41; but in 2014: 1.42:33.56:65.02. Changsha in 2007: 6.34:44.96:48.7; but in 2014: 4.0:54.3:41.7. They are capital cities, but three industry structures for them have different variations. Similarly in Wuhan and Changsha, proportions for the primary and tertiary industries present declining trend but the secondary industry increasing trend. In Guangzhou, proportions for the primary and secondary industries are declining while the tertiary industry is evidently elevating. In addition to the three capital cities, 5 other cities along this train line such as Yueyang, Zhuzhou, Hengyang, Chenzhou and Shaoguan have different proportion variations for the three industries.

Table 2 The proportion of industrial structure of the main city that before and after the Wuhan-Guangzhou high-speed train opened

\begin{tabular}{|c|c|c|c|c|c|c|c|c|c|}
\hline \multirow[t]{2}{*}{ city } & \multicolumn{3}{|c|}{2 years ago ( 2007$)$} & \multicolumn{3}{|c|}{ After 1 year ( 2010$)$} & \multicolumn{3}{|c|}{ After 5 years ( 2014 ) } \\
\hline & $\begin{array}{c}\text { Primar } \\
\mathrm{y} \\
\text { Industry }\end{array}$ & $\begin{array}{c}\text { Seconda } \\
\text { ry } \\
\text { Industry }\end{array}$ & $\begin{array}{c}\text { Tertiar } \\
\mathrm{y} \\
\text { Industry }\end{array}$ & $\begin{array}{c}\text { Primar } \\
\mathrm{y} \\
\text { Industry }\end{array}$ & $\begin{array}{l}\text { Secondary } \\
\text { Industry }\end{array}$ & $\begin{array}{c}\text { Tertiar } \\
\mathrm{y} \\
\text { Industry }\end{array}$ & $\begin{array}{c}\text { Primar } \\
\text { y } \\
\text { Industry }\end{array}$ & $\begin{array}{l}\text { Secondal } \\
\text { y Industr. }\end{array}$ & $\begin{array}{l}\text { Tertiary } \\
\text { Industry }\end{array}$ \\
\hline Wuhan & 4.11 & 45.83 & 50.06 & 3.06 & .5 .51 & 51.44 & 3.5 & 47.5 & 49.0 \\
\hline Yueyang & 19.34 & 48.55 & 32.11 & 14 & $i 4.19$ & 31.8 & 10.9 & 54.0 & 35.1 \\
\hline Changsha & 6.34 & 44.96 & 48.7 & 4.44 & $i 3.6$ & 41.96 & 4.0 & 54.3 & 41.7 \\
\hline Zhuzhou & 12.86 & 52.75 & 34.39 & 9.71 & $i 7.77$ & 32.52 & 7.9 & 59.3 & 32.8 \\
\hline Hengyang & g 23.44 & 40.05 & 36.51 & 18.62 & .5 .46 & 35.92 & 15.2 & 46.8 & 38.0 \\
\hline Chenzhou & u 15.44 & 50.41 & 34.15 & 11.72 & $i 4.95$ & 33.33 & 9.7 & 56.8 & 33.5 \\
\hline Shaoguan & 14.19 & 48.47 & 37.34 & 14.04 & $\cdot 1.78$ & 44.18 & 12.9 & 40.6 & 46.5 \\
\hline Guangzhoı & 2.11 & 39.48 & 58.41 & 1.75 & $i 7.24$ & 61.01 & 1.42 & 33.56 & 65.02 \\
\hline
\end{tabular}

Overall, changes of the industrial structures for the main cities along the train line cannot contribute to the construction and operation of the HST, but its open does accelerate the transition and optimization of the three industries to some extent. Owing to different facilities and synthetic conditions, various industrial restructurings occur among the cities along the same train line. Another example, since the opening of Beijing-Shanghai HST, Ji'nan, one of the related cities, has shorten the arrival time at surrounding cities. With its influence radius enlarging, and radiometric force gradually enhancing, the industrial structures in Ji'nan has been constantly optimizing. The city of Taian, close to Ji'nan, has been incorporated into the "Economic Circle of Half Hour" of the capital of Shandong Province; and meanwhile, affected by the radiation of Beijing-Tianjin-Hebei Metropolitan Area, not only has HST brought about great benefits, but also its proportion of three industries has been reasonably regulating and optimizing.

\section{Conclusion}

Based on sorting and analysis of HST's influence on regional economics, this article has conducted causality test by construction model and related statistic data. Through scientific analyzation we find that construction and operation of HST has greatly accelerated the development of regional economics and contributed to the optimization and upgrade of the industrial structures, in addition to the promotion of regional economic aggregate. The following are our conclusions:

1. HST's influence on regional economic development is characterized by multi-dimensional features. The investment and construction of HST has profound influences on such factors as boost of regional economic aggregate, optimization of regional industrial structures, guidance of spatial and temporal pattern, mobility of production factors, and adjustment of urban and rural structures.

2. HST's influence on urban industrial structures along the train lines exhibits a remarkable characteristic of gradient progression and psychological Halo Effect. Apparently, the construction and operation of HST has lead to the proportional changes among the cities along the train lines, with the 
tendency that the longer operation time is, the greater the change. Besides, this influence on the

Tertiary Industry shows its moderate speed and positive correlation and the next consequently the Secondary and Primary Industries.

\section{References}

[1] Nakamura H, T Ueda. The impacts of Shinkansin on regional development. Proceedings of WCTR, 1989(3): 95-109.

[2] Gutierrez Javier, Rafael Gonzalez, Gabriel Gomez. The European high-speed train network. Journal of Transport Geography, 2015(4): 227-238.

[3] Bonnafous A. The regional impact of the TGV. Transportation, 1987, 14: 127-137. 